\title{
MicroRNA-1296 expression is associated with prognosis and inhibits cell proliferation and invasion by Wnt signaling in non-small cell lung cancer
}

\author{
HAIQING DENG, CHANGPING XIE, YI YE and ZHENGLONG DU
}

Department of Cardiothoracic Surgery, The Second People's Hospital of Qinzhou, Qinzhou, Guangxi 535000, P.R. China

Received November 17, 2018; Accepted June 20, 2019

DOI: $10.3892 / \mathrm{ol} .2019 .11154$

\begin{abstract}
MicroRNAs (miRNAs) are vital regulators of non-small cell lung cancer (NSCLC) development and tumorigenesis. The aim of the present study was to explore the role of miRNA (miR)-1296 expression in NSCLC. The expression of miR-1296 was detected by reverse transcription-quantitative PCR in NSCLC tissues and matched normal tissues. The association of miR-1296 expression with clinicopathological factors of NSCLC patients was evaluated by the $\chi^{2}$ test. Prognostic value of miR-1296 expression levels in patients with NSCLC was assessed using the Kaplan-Meier method and a Cox proportional hazards model; Cell Counting Kit-8, Transwell migration and western blot assays were used to detect the association between miR-1296 and cell proliferation, invasion and Wnt signaling in NSCLC, respectively. The results of the present study demonstrated that miR-1296 expression was significantly downregulated in NSCLC tissues and cells compared to corresponding controls. Lower miR-1296 expression exhibited a significant association with lymph node metastasis and tumor-node-metastasis stage of patients with NSCLC. In addition, the survival analysis demonstrated that low miR-1296 expression predicted a poorer prognosis compared to high miR-1296 expression. Multivariate Cox analysis also demonstrated that reduced miR-1296 expression was an independent risk factor of NSCLC prognosis. Additionally, miR-1296 inhibited cell proliferation, invasion and Wnt signaling in NSCLC. Thus, the results of the present study indicated that miR-1296 expression may be a potential biomarker of NSCLC prognosis and potential target for NSCLC treatment.
\end{abstract}

Correspondence to: Professor Zhenglong Du, Department of Cardiothoracic Surgery, The Second People's Hospital of Qinzhou, 219 Wenfeng Nan Road, Qinnan, Qinzhou, Guangxi 535000, P.R. China

E-mail: yin95naihaoshanp@163.com

Key words: non-small cell lung cancer, microRNA-1296, cell proliferation, prognosis, Wnt signaling

\section{Introduction}

Lung cancer is one of the most rapidly growing types of cancer and exhibits a high cancer-associated morbidity rate worldwide (1). Non-small cell lung cancer (NSCLC) accounts for $\sim 80 \%$ of lung cancer cases (2). Treatment methods, including surgery, radiotherapy, chemotherapy and molecular targeted therapy, have improved the overall survival rate, but prognosis for patients diagnosed at an advanced stage remains poor $(3,4)$. Therefore, it is urgent to investigate novel biomarkers for diagnosis and prediction of prognosis for patients with NSCLC.

MicroRNAs (miRNAs) are a class of small non-coding RNAs involved in post-transcriptional regulation of gene expression through interactions with the $3^{\prime}$ untranslated regions (3'UTRs) of target mRNAs $(5,6)$. In NSCLC, certain miRNAs have been identified as biomarkers or therapeutic targets; for example, high expression levels of miRNA (miR)-18a, miR-20a and miR-92a correlate with poor prognosis in patients with NSCLC (7). High expression of miR-493-5p may improve clinical prognosis of NSCLC by targeting the oncogene integrin subunit b1 (8). miR-410 acts as an oncogene in NSCLC by downregulating solute carrier family 34 member through the activation of the Wnt/ $\beta$-catenin pathway (9). However, the functional effects and underlying role of miR-1296 in NSCLC remain unknown. Therefore, the present study investigated the function of miR-1296 in NSCLC.

The results of the present study demonstrated that miR-1296 expression was significantly downregulated in NSCLC tissues and cells. In addition, survival analysis revealed that reduced miR-1296 expression was associated with a poor prognosis in patients with NSCLC. Multivariate Cox analysis demonstrated that reduced miR-1296 expression was an independent risk factor of NSCLC prognosis. Overexpression of miR-1296 inhibited cell proliferation, invasion and Wnt signaling in NSCLC. In conclusion, these results indicated that miR-1296 expression may be a potential biomarker of NSCLC prognosis and potential target of NSCLC treatment.

\section{Materials and methods}

Patients and tissue samples. NSCLC and adjacent normal tissue samples were collected from 106 NSCLC patients 
(54 male and 52 female) who underwent surgical resection at the Department of Cardiothoracic Surgery, The Second People's Hospital of Qinzhou (Qinzhou, China) between December 2010 and December 2014. Following surgical resection, the tissue samples were immediately frozen and stored at $-80^{\circ} \mathrm{C}$ until RNA extraction. The age of the patients ranged between 26 and 80 years (mean age, 50.5 years). The experiments were approved by the Ethics Committee of The Second People's Hospital of Qinzhou. Written informed consent was obtained from all patients. Clinical stages were classified according to the World Health Organization Tumor-Node-Metastasis (TNM) criteria (10).

Cell culture and transfection. Four human NSCLC cell lines: A549, H1299, H460 and SK-MES-1, and an immortalized and non-tumorigenic human bronchial epithelial cell line NL20 were purchased from American Type Culture Collection. The cell lines were cultured in RPMI-1640 (Gibco; Thermo Fisher Scientific, Inc.) medium supplemented with $10 \%$ FBS (Gibco; Thermo Fisher Scientific, Inc.) at $37^{\circ} \mathrm{C}$ in $5 \% \mathrm{CO}_{2}$. A total of $1 \times 10^{6}$ cells were transfected with $100 \mathrm{nM}$ miRNA-negative control (miR-NC), miR-1296 mimic (100 nM) or miR-1296 inhibitor (100 nM; Chang Jing Bio-Tech, Ltd.) using Lipofectamine $^{\circledR} 3000$ reagent (Invitrogen; Thermo Fisher Scientific, Inc.) according to the manufacturer's instructions. The cells were harvested for RT-qPCR or western blot analysis to assess the mRNA and protein expression $48 \mathrm{~h}$ following transfection.

$R N A$ extraction and reverse transcription-quantitative $P C R$ $(R T-q P C R)$. Total RNA was extracted from tissues and cells using TRIzol ${ }^{\circledR}$ reagent (Invitrogen; Thermo Fisher Scientific, Inc.) according to the manufacturer's protocol. The RNA was reverse transcribed to generate cDNA using Prime Script RT-PCR kit (Takara Biotechnology Co., Ltd.) according to the manufacturer's protocol The thermocycling conditions were as follows: $95^{\circ} \mathrm{C}$ for $5 \mathrm{~min}$, followed by 40 cycles of $95^{\circ} \mathrm{C}$ for $10 \mathrm{sec}$ and $60^{\circ} \mathrm{C}$ for $30 \mathrm{sec}$. U6 small nuclear RNA was used as an internal control. U6 forward, 5'-CTCGCTTCGGCAGCA CA-3', and reverse, 5'-AAACGCTTCACGAATTTGCGT-3'. miR-1296 primers were purchased from Takara Biotechnology Co., Ltd. The mRNA expression fold changes were calculated using the $2^{-\Delta \Delta \mathrm{Cq}}$ method (11).

Cell proliferation assay. Cell proliferative ability was evaluated by using Cell Counting Kit-8 (CCK-8; Dojindo Molecular Technologies, Inc.) according to the manufacturer's instructions. Briefly, transfected cells $\left(3 \times 10^{3}\right.$ cells/well $)$ were seeded in 96-well plates. Following cell were culture for 1, 2, 3 and 4 days, CCK- 8 solution was added to each well and then incubated for $2 \mathrm{~h}$ at $37^{\circ} \mathrm{C}$ in a humidified atmosphere with $5 \%$ $\mathrm{CO}_{2}$. Cell proliferation was detected by a VICTOR microplate reader (BioTek Instruments, Inc.) and absorbance was measured at $450 \mathrm{~nm}$.

Transwell assay. Transwell cell invasion assay was performed using a 24-well Transwell chamber (Costar; Corning, Inc.) with Matrigel (BD Biosciences). Transfected cells ( $1 \times 10^{5}$ cells/well) in serum-free medium were seeded in the upper chamber. Medium with $10 \%$ FBS was added to the lower chamber. The cells were maintained at $37^{\circ} \mathrm{C}$ in a humidified atmosphere with $5 \% \mathrm{CO}_{2}$ for $48 \mathrm{~h}$. The cells in the lower chamber were fixed with $100 \%$ methanol for $20 \mathrm{~min}$ at $4^{\circ} \mathrm{C}$, stained using $1 \%$ crystal violet for $15 \mathrm{~min} 4^{\circ} \mathrm{C}$ and counted using a light microscope (Olympus Corporation).

Western blot analysis. Transfected cells were lysed in radioimmunoprecipitation assay buffer according to the manufacturer's instructions. Protein concentrations were determined using a Nanodrop 2000 spectrophotometer (Thermo Fisher Scientific, Inc) by measuring optical density at a wavelength of $280 \mathrm{~nm}$. Protein $(30 \mu \mathrm{g} / \mathrm{lane})$ was separated by SDS-PAGE on $10 \%$ gels and transferred onto polyvinylidene fluoride membrane. The membranes were blocked with $5 \%$ skimmed milk at room temperature for $1.5 \mathrm{~h}$ and incubated with specific primary antibodies against transcription factor 4 (TCF4; 1:1,000; cat. no. sc-8631, Santa Cruz Biotechnology, Inc., CA, USA), $\beta$-catenin (1:500; cat. no. sc-16512, Santa Cruz Biotechnology, Inc., CA, USA) and GAPDH (1:1,000; cat. no. sc-16512 2118S, Cell Signaling Technology, Inc., CA, USA) overnight at $4^{\circ} \mathrm{C}$. Primary antibody incubation was followed by incubation with horseradish peroxidase-conjugated secondary antibodies (1:1,000; cat. no. sc-2357; Santa Cruz Biotechnology, Inc.) at room temperature for $1 \mathrm{~h}$. The proteins were detected using an enhanced chemiluminescence (ECL) detection system (Bio-Rad Laboratories, Inc.) and an ECL kit (cat. no. 32106; Thermo Fisher Scientific, Inc.). ImageJ software (version 1.48; National Institutes of Health Bethesda) was used to measure the band density. GAPDH was used as a loading control.

Statistical analysis. The data were analyzed using SPSS 18.0 software (SPSS, Inc.). The results are presented as the mean \pm standard deviation. Differences between two groups were analyzed using Student's t-test; differences among $\geq 3$ groups were analyzed using one-way analysis of variance, followed by multiple comparisons by the Student-Newman-Keuls test. The $\chi^{2}$ test was used to evaluate the association between miR-1296 and clinical factors. The Kaplan-Meier method was used to plot the survival curves, and the log-rank test was used for overall survival analysis. $\mathrm{P}<0.05$ was considered to indicate a statistically significant difference.

\section{Results}

miR-1296 expression is downregulated in patients with NSCLC and in NSCLC cells. To analyze the role of miR-1296 expression in NSCLC, the expression levels of miR-1296 in NSCLC tissues and adjacent normal tissues were evaluated by RT-qPCR. The results demonstrated that miR-1296 expression levels in NSCLC tissues were significantly lower compared with in adjacent normal tissues $(\mathrm{P}<0.05$; Fig. 1A). In addition, four human NSCLC cell lines exhibited significantly downregulated miR-1296 expression compared with the normal control NL20 cell line (Fig. 1B). Thus, these results indicated that low miR-1296 expression levels may potentially serve as a prognostic marker for patients with NSCLC.

Downregulation of miR-1296 expression is associated with TNM stage and lymph-node metastasis of patients with NSCLC. Patient with NSCLC were classified into two 
A

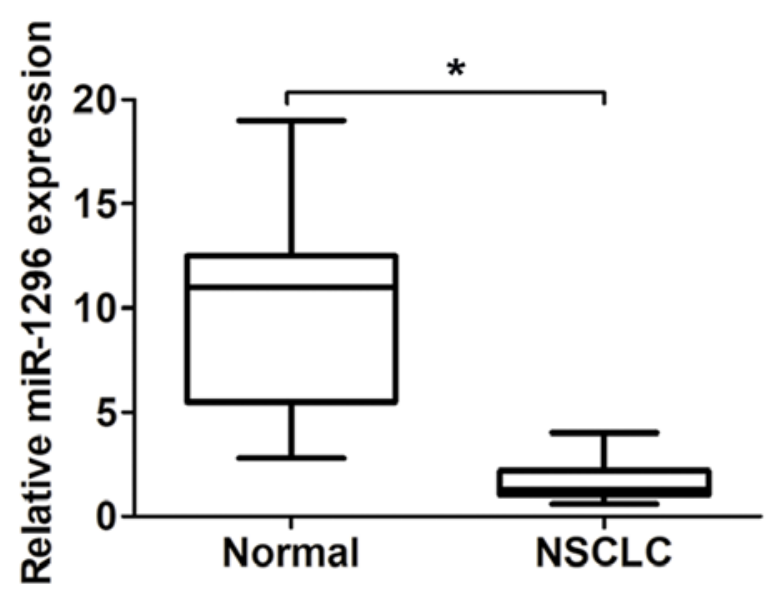

B

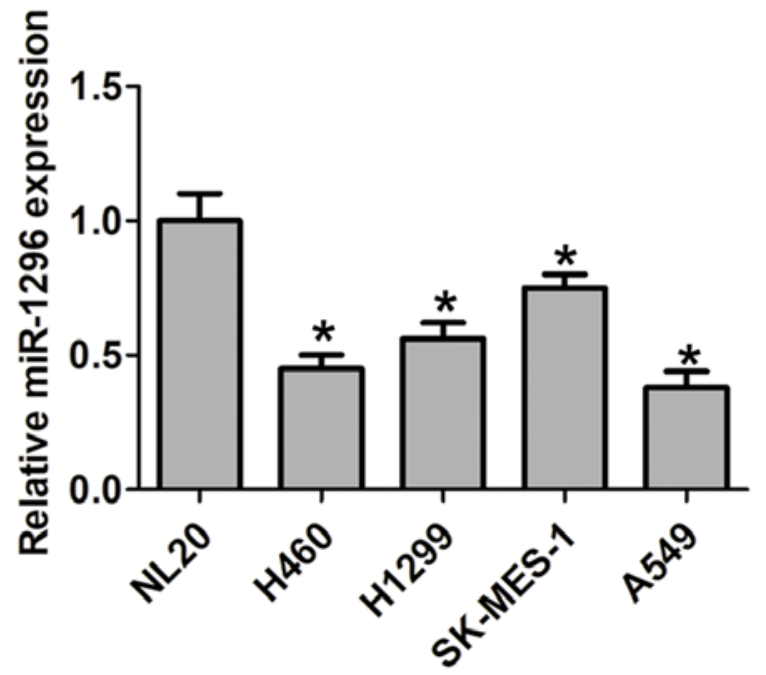

Figure 1. miR-1296 expression is downregulated in NSCLC tissues and cells. (A) RT-qPCR analysis of miR-1296 expression in NSCLC tissues and adjacent normal tissues $(\mathrm{n}=108)$. (B) RT-qPCR analysis of miR-1296 expression in an immortalized non-tumorigenic human bronchial epithelial cell line NL20 and human NSCLC cell lines A549, H1299, H460 and SK-MES-1. * $\mathrm{P}<0.05$ vs. normal tissue or NL20. RT-qPCR, reverse transcription-quantitative PCR; miR, microRNA; NSCLC, non-small cell lung cancer.

A

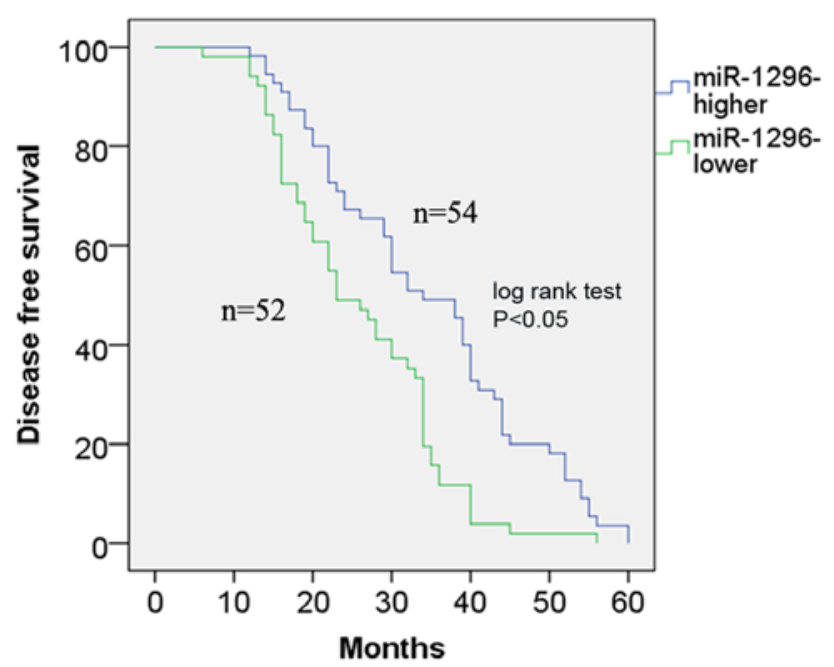

B

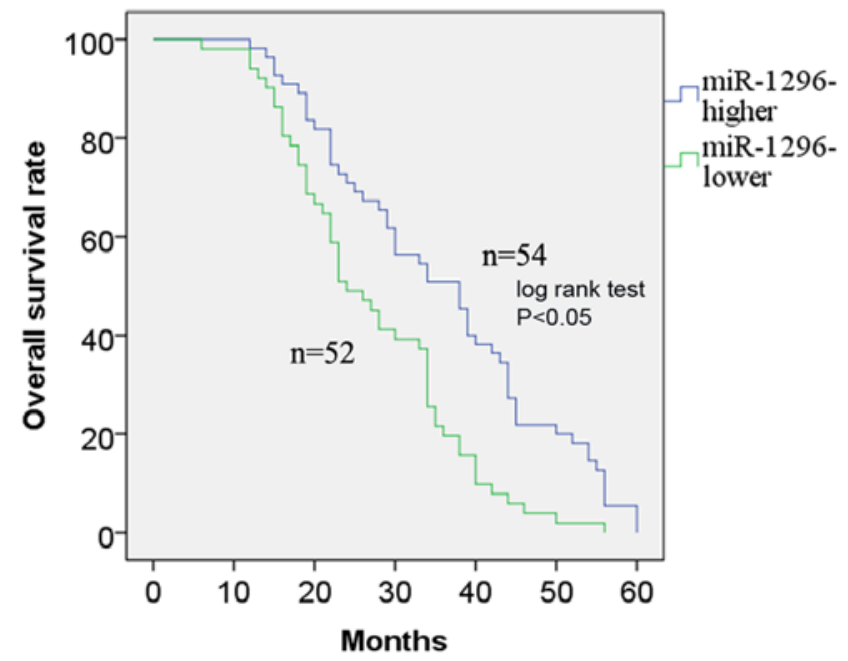

Figure 2. Low miR-1296 expression is associated with poor prognosis in patients with NSCLC. (A) Kaplan-Meier survival curves and log-rank test demonstrated lower disease-free survival rate of patients with NSCLC with low miR-1296 expression compared with patients with high miR-1296 expression. (B) Kaplan-Meier survival curves demonstrated lower overall survival rate of patients with NSCLC with low miR-1296 expression compared with patients with high miR-1296 expression. NSCLC, non-small cell lung cancer; miR, microRNA.

groups by miR-1296 expression (high and low) based on the median expression of miR-1296 in all NSCLC tissue samples. Clinicopathological characteristic analysis demonstrated that low miR-1296 expression was closely associated with lymph-node metastasis $(\mathrm{P}=0.001$; Table $\mathrm{I})$ and advanced TNM stage $(\mathrm{P}=0.006$; Table $\mathrm{I})$. By contrast, no association was observed between miR-1296 expression and other clinicopathological features, including sex, age, tumor differentiation and tumor size (Table I). with NSCLC. The Kaplan-Meier method was used to plot the survival curves, which were further analyzed by the log-rank test. The results demonstrated that low miR-1296 expression was associated with poor disease-free survival (DFS; $\mathrm{P}<0.05$; Fig. 2A) and overall survival (OS; P<0.05; Fig. 2B) of patients with NSCLC compared with high miR-1296 expression. Univariate and multivariate Cox proportional hazards regression model analysis revealed that lymph node metastasis $[\mathrm{P}=0.001$; hazard ratio $(\mathrm{HR})=2.038 ; 95 \%$ confidence interval (CI), 0.712-3.664], advanced TNM stage $(\mathrm{P}=0.001$; $\mathrm{HR}=2.113$; 95\% CI, 0.812-3.544) and low miR-1296 expression $(\mathrm{P}=0.001 ; \mathrm{HR}=2.263 ; 95 \% \mathrm{CI}, 1.125-3.732)$ were independent predictors of poor DFS in NSCLC (Table II). In 
Table I. Association between clinicopathological characteristics of 106 patients and miR-1296 expression levels in non-small cell lung cancer.

\begin{tabular}{|c|c|c|c|c|}
\hline Characteristics & Total patients $(\mathrm{n}=106)$ & High miR-1296 $(n=54)$ & Low miR-1296 (n=52) & P-value \\
\hline Age (years) & & & & 0.849 \\
\hline$\leq 50$ & 54 & 28 & 26 & \\
\hline$>50$ & 52 & 26 & 26 & \\
\hline Sex & & & & 0.301 \\
\hline Male & 64 & 30 & 34 & \\
\hline Female & 42 & 24 & 18 & \\
\hline Tumor differentiation & & & & 0.079 \\
\hline High-middle & 66 & 38 & 28 & \\
\hline Poor & 40 & 16 & 24 & \\
\hline Tumor size $(\mathrm{cm})$ & & & & 0.248 \\
\hline$<3$ & 57 & 32 & 25 & \\
\hline$\geq 3$ & 49 & 22 & 27 & \\
\hline Lymph node metastasis & & & & $0.001^{\mathrm{a}}$ \\
\hline No & 62 & 40 & 22 & \\
\hline Yes & 44 & 14 & 30 & \\
\hline Tumor-node-metastasis stage & & & & $0.006^{\mathrm{a}}$ \\
\hline $\mathrm{I} / \mathrm{II}$ & 61 & 38 & 23 & \\
\hline III/IV & 45 & 16 & 29 & \\
\hline
\end{tabular}

${ }^{\mathrm{a}} \mathrm{P}<0.05 . \mathrm{miR}-1296$, microRNA-1296.

Table II. Univariate and multivariate Cox analysis of disease-free survival in 106 patients with non-small cell lung cancer.

\begin{tabular}{|c|c|c|c|c|}
\hline \multirow[b]{2}{*}{ Characteristics } & \multicolumn{2}{|c|}{ Univariate Cox analysis } & \multicolumn{2}{|c|}{ Multivariate Cox analysis } \\
\hline & $\mathrm{HR}(95 \% \mathrm{CI})$ & P-value & $\mathrm{HR}(95 \% \mathrm{CI})$ & P-value \\
\hline Age (years) & $0.766(0.544-1.245)$ & 0.612 & & \\
\hline Sex & $0.644(0.352-1.446)$ & 0.794 & & \\
\hline Tumor differentiation & $0.993(0.764-1.544)$ & 0.446 & & \\
\hline Tumor size $(\mathrm{cm})$ & $1.019(0.688-1.836)$ & 0.278 & & \\
\hline Lymph node metastasis & $2.234(0.885-3.864)$ & $0.001^{\mathrm{a}}$ & $2.038(0.712-3.664)$ & $0.001^{\mathrm{a}}$ \\
\hline TNM stage & $2.543(1.255-4.222)$ & $0.001^{\mathrm{a}}$ & $2.013(0.812-3.544)$ & $0.001^{\mathrm{a}}$ \\
\hline Low miR-1296 levels & $2.688(1.644-4.388)$ & $0.001^{\mathrm{a}}$ & $2.013(1.125-3.732)$ & $0.001^{\mathrm{a}}$ \\
\hline
\end{tabular}

${ }^{\text {a }} \mathrm{P}<0.05$. HR, hazard ratio; CI, confidence interval; miR-1296, microRNA-1296.

addition, lymph node metastasis $(\mathrm{P}=0.001 ; \mathrm{HR}=1.932 ; 95 \%$ CI, 0.872-3.145), advanced TNM stage $(\mathrm{P}=0.001 ; \mathrm{HR}=2.063$; 95\% CI, 0.995-3.448) and low miR-1296 expression ( $\mathrm{P}=0.001$; $\mathrm{HR}=2.138$; 95\% CI, 1.042-4.349) were independent predictors of poor overall survival rate in NSCLC (Table III). These results suggested that low miR-1296 expression may be an independent predictor for poor prognosis in patients with NSCLC.

miR-1296 suppresses cell proliferation and invasion in NSCLC cells. To further investigate the effects of miR-1296 expression in NSCLC cells, CCK-8 cell proliferation and Transwell assays were performed. SK-MES-1 and A549 cells were transfected with a miR-1296 mimic or miR-1296 inhibitor for upregulation or downregulation of miR-1296 expression levels, as they exhibited higher or lower expression of miR-1296 compared with the other two cell lines (Fig. 3A and B). The results of the CCK-8 assay indicated that miR-1296 overexpression in SK-MES-1 and A549 cells inhibited cell proliferation, whereas reduced miR-1296 expression enhanced cell proliferation compared with respective negative control groups (Fig. 3C and D). Additionally, Transwell cell invasion assay demonstrated that miR-1296 overexpression in SK-MES-1 and A549 cells inhibited cell invasive ability, whereas reduced 
Table III. Univariate and multivariate Cox analysis of overall survival in 106 patients with non-small cell lung cancer.

\begin{tabular}{|c|c|c|c|c|}
\hline \multirow[b]{2}{*}{ Characteristics } & \multicolumn{2}{|c|}{ Univariate analysis } & \multicolumn{2}{|c|}{ Multivariate analysis } \\
\hline & HR (95\% CI) & P-value & $\mathrm{HR}(95 \% \mathrm{CI})$ & P-value \\
\hline Age (years) & $0.665(0.346-1.224)$ & 0.732 & & \\
\hline Sex & $0.786(0.422-1.411)$ & 0.694 & & \\
\hline Tumor differentiation & $1.115(0.563-1.766)$ & 0.546 & & \\
\hline Tumor size $(\mathrm{cm})$ & $1.203(0.763-1.926)$ & 0.345 & & \\
\hline Lymph node metastasis & $2.096(1.002-3.665)$ & $0.001^{\mathrm{a}}$ & $1.932(0.872-3.145)$ & $0.001^{\mathrm{a}}$ \\
\hline TNM stage & $2.315(1.075-3.886)$ & $0.001^{\mathrm{a}}$ & $2.063(0.995-3.448)$ & $0.001^{\mathrm{a}}$ \\
\hline Low miR-1296 levels & $2.549(1.393-4.504)$ & $0.001^{\mathrm{a}}$ & $2.138(1.042-4.349)$ & $0.001^{\mathrm{a}}$ \\
\hline
\end{tabular}

${ }^{a} \mathrm{P}<0.05$. HR, hazard ratio; CI, confidence interval; miR-1296, microRNA-1296.

A

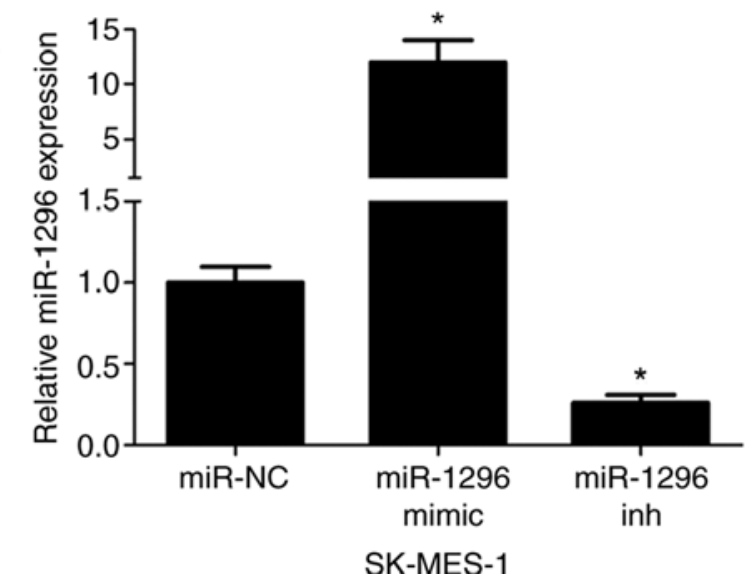

C

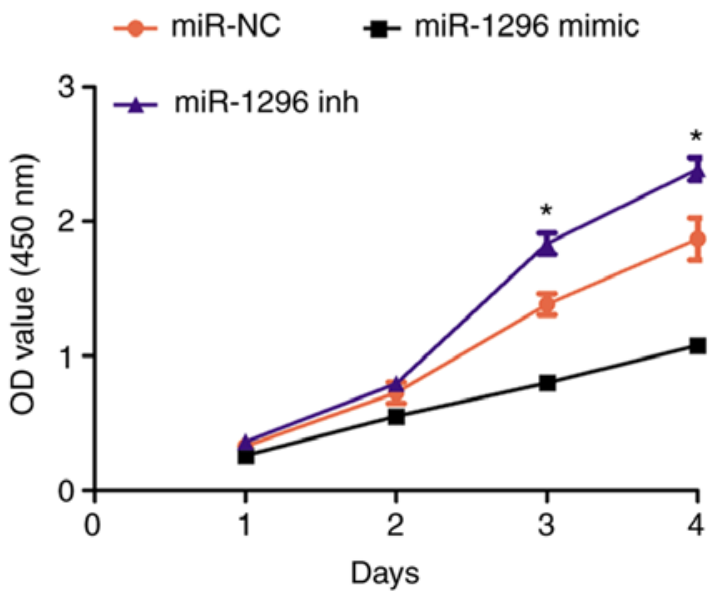

SK-MES-1

\section{B}

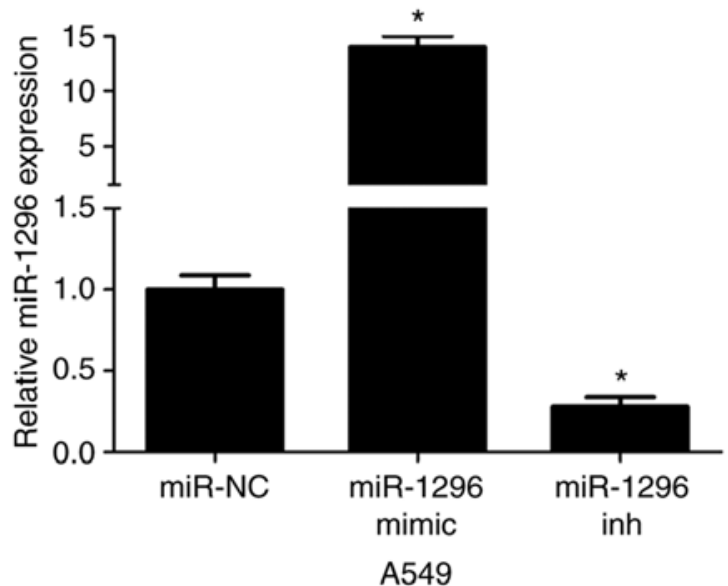

D

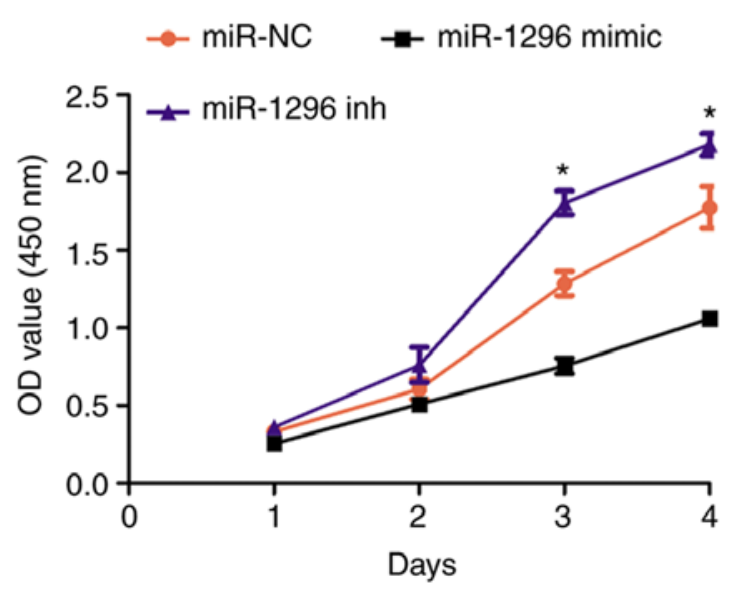

A549

Figure 3. miR-1296 overexpression suppresses proliferative ability in non-small cell lung cancer cells. Reverse transcription-quantitative PCR analysis of miR-1296 expression in (A) SK-MES-1 and (B) A549 cells following transfection with miR-NC, miR-1296 mimic or miR-1296 inhibitor. Cell Counting Kit-8 analysis of cell proliferation in (C) SK-MES-1 and (D) A549 cells following transfection with miR-NC, miR-1296 mimic or miR-1296 inhibitor. * $<0.05$ vs. miR-NC. miR, microRNA; NC, negative control; inh, inhibitor; OD, optical density.

miR-1296 expression enhanced cell invasive ability compared with respective negative control groups (Fig. 4). Thus, these results indicated that miR-1296 may suppress cell proliferation and invasion of NSCLC cells.
miR-1296 suppresses Wnt signaling in NSCLC cells. To investigate the effects of miR-1296 expression in the Wnt signaling pathway, western blot analysis of downstream factors $\beta$-catenin and TCF4 was performed. The results indicated that 
A

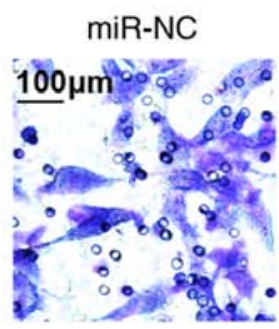

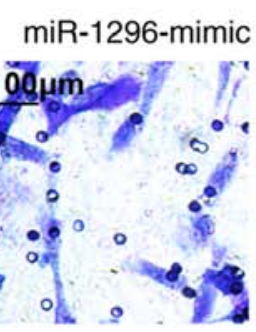

SK-MES-1

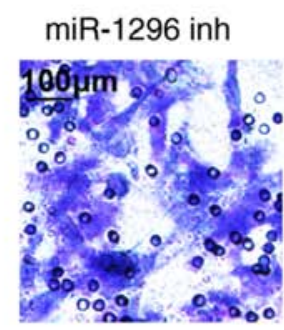

miR-1296 inh

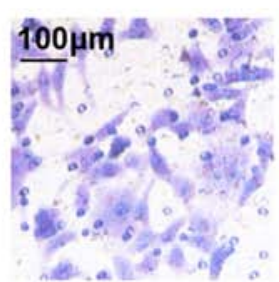

A549

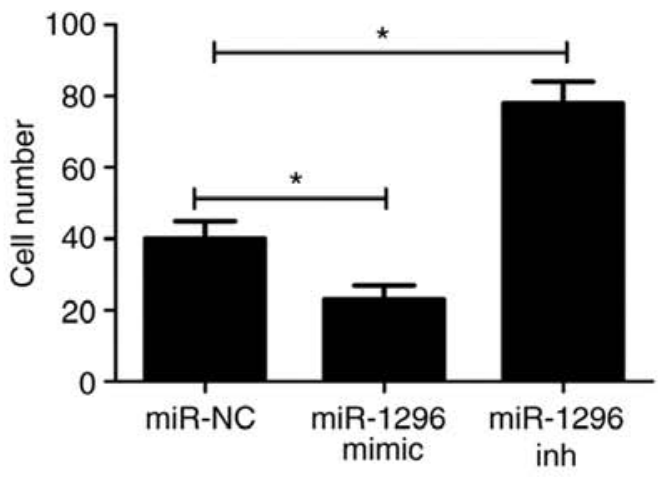

SK-MES-1

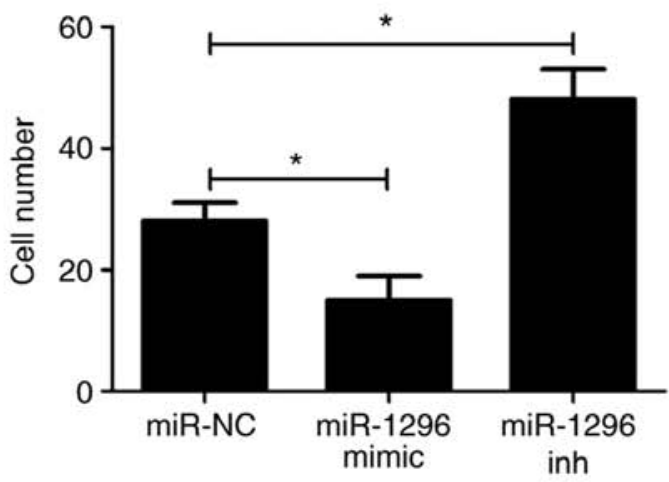

A549

Figure 4. miR-1296 overexpression suppresses invasion in non-small cell lung cancer cells. (A) Transwell invasion assay results from SK-MES-1 cells transfected with miR-NC, miR-1296 mimic or miR-1296 inhibitor. (B) Transwell invasion assay results from A549 cells transfected with miR-NC, miR-1296 mimic or miR-1296 inhibitor. Scale bar, $100 \mu \mathrm{m}$. ${ }^{*} \mathrm{P}<0.05$ vs. miR-NC. miR, microRNA; NC, negative control; inh, inhibitor.

miR-1296 overexpression inhibited Wnt signaling pathway by reducing $\beta$-catenin and TCF4 expression in SK-MES-1 and A549 cells compared with respective control groups. By contrast, downregulation of miR-1296 significantly increased $\beta$-catenin and TCF4 protein expression levels in SK-MES-1 and A549 cells compared with the control groups (Fig. 5). These results indicated that miR-1296 may suppress Wnt signaling in NSCLC cells.

\section{Discussion}

Abnormal gene expression in cancer involves inactivation of tumor suppressor genes and activation of oncogenes (12). miRNAs are key regulators of tumor progression in NSCLC, and certain miRNAs are valuable for diagnostics and treatment of NSCLC (13). A previous study revealed that dysregulation of miRNA expression may be used as sensitive and accurate biomarkers or prognostic predictors of human NSCLC (14). For example, miR-137 is downregulated and its promoter is hypomethylated in lung cancer, and high levels of miR-137 promoter methylation are associated with poor disease-free survival in NSCLC (15); plasma exosomal microRNA-451a is a noninvasive biomarker for early prediction of recurrence and prognosis in non-small cell lung cancer (NSCLC) patients after curative resection (16). Serum miR-494 was significantly elevated in NSCLC patients and closely correlated with poor clinical outcome (17).

miR-1296 has been identified as a tumor suppressor in several types of cancer; for example, miR-1296-5p may be involved in the regulation of migration and invasion of human gastric cancer cells at least in part by targeting the erb-b2 receptor tyrosine kinase 2 (ERBB2)/Rac family small GTPase 1 signaling pathway (18). miR-1296-5p is involved in the regulation of proliferation of breast cancer cells by targeting the ERBB2/MTOR complex 1 signaling pathway (19). Downregulation of miR-1296 may serve as a prognostic biomarker in hepatocellular carcinoma (HCC) and miR-1296 inhibits metastasis and epithelial-mesenchymal transition in HCC by targeting the SRSF protein kinase 1-mediated PI3K/AKT pathway (20). In the present study, miR-1296 expression was significantly downregulated in NSCLC tissues compared to adjacent normal tissues. In addition, miR-1296 expression was downregulated in NSCLC cell lines compared with a normal lung cell line. Survival analysis demonstrated that low miR-1296 expression predicted poor prognosis. Additionally, multivariate Cox analysis revealed that low miR-1296 expression was an independent risk factor of NSCLC prognosis. Thus, these results indicated that miR-1296 expression level may be a potential biomarker for NSCLC prognosis.

The present study demonstrated that miR-1296 overexpression inhibits cell proliferation and invasion, whereas reduced miR-1296 expression enhanced cell proliferation and invasion compared with the control groups. Wnt signaling pathway is involved in tumor cell proliferation and invasion in NSCLC (21); in the present study, miR-1296 overexpression inhibited Wnt signaling by reducing the expression levels of two key proteins, $\beta$-catenin and TCF4, in NSCLC cells. By 
A

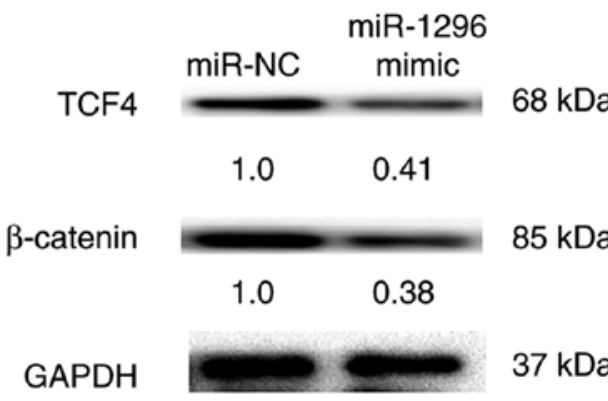

SK-MES-1

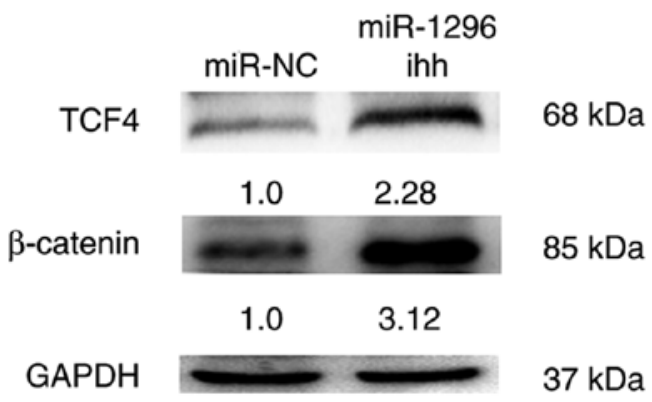

SK-MES-1
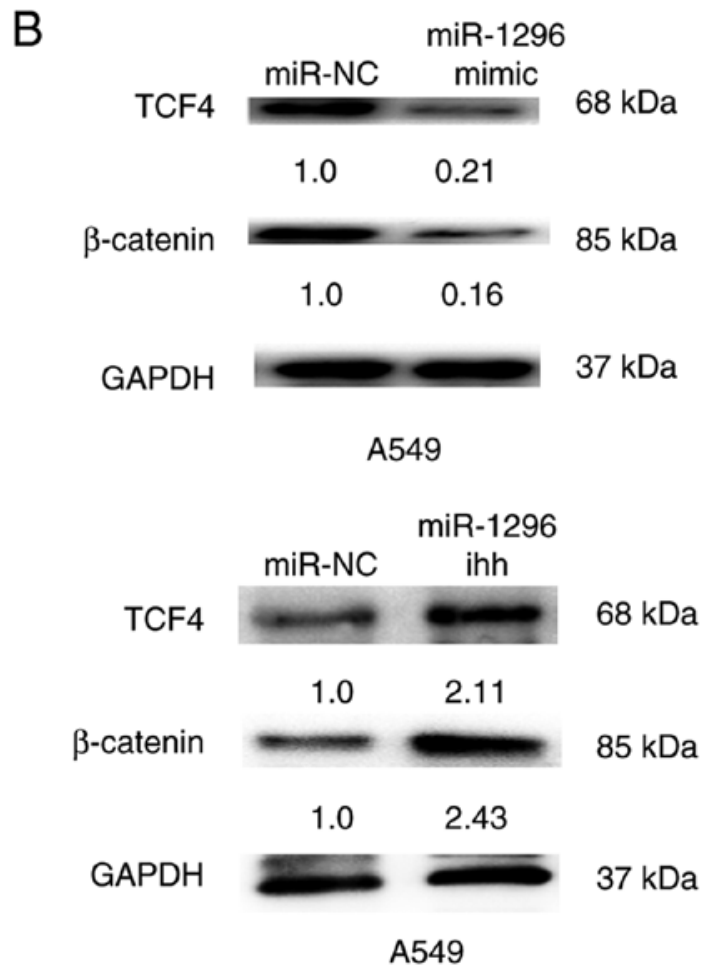

D TCF4 $\beta$-catenin

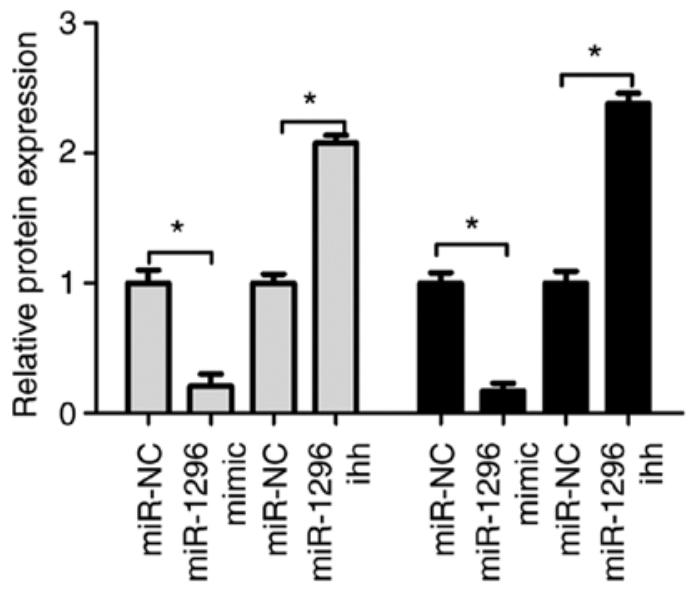

A549

Figure 5. miR-1296 overexpression suppresses Wnt signaling in non-small cell lung cancer cells. (A) Western blot analysis results of TCF4 and $\beta$-catenin protein expression levels in SK-MES-1 cells transfected with miR-NC and miR-1296 mimic or miR-1296 inhibitor. (B) Western blot analysis results of TCF-4 and $\beta$-catenin protein expression levels in A549 cells transfected with miR-NC and miR-1296 mimic or miR-1296 inhibitor. (C) Relative protein expression of TCF4 and $\beta$-catenin in SK-MES-1 cells transfected with miR-NC and miR-1296 mimic or miR-1296 inhibitor. (D) Relative protein expression of TCF4 and $\beta$-catenin in A549 cells transfected with miR-NC and miR-1296 mimic or miR-1296 inhibitor. ${ }^{*} \mathrm{P}<0.05$ vs. NC. miR, microRNA; NC, negative control; inh, inhibitor; TCF4, transcription factor 4.

contrast, downregulation of miR-1296 significantly promoted Wnt signaling by increasing $\beta$-catenin and TCF4 expression in NSCLC cells.

In conclusion, the present study demonstrated that miR-1296 expression was reduced in NSCLC tissues and cell lines compared with healthy tissues and cells. In addition, low miR-1296 expression was associated with advanced TNM stage and lymph-node metastasis of patients with NSCLC. miR-1296 expression level was identified as a prognostic predictor of NSCLC. Overexpression of miR-1296 inhibited cell proliferation, invasion and Wnt signaling in NSCLC. These results indicated that miR-1296 expression may be a potential biomarker for NSCLC prognosis, as well as a potential target of NSCLC treatment.

\section{Acknowledgements}

Not applicable. 


\section{Funding}

No funding was received.

\section{Availability of data and materials}

The datasets used and/or analyzed during the present study are available from the corresponding author on reasonable request.

\section{Authors' contributions}

HD, YY and ZD conceived and designed the study, and drafted the manuscript. HD, YY, CX and ZD collected, analyzed and interpreted the data and critically revised the manuscript. All authors have read and approved the final manuscript.

\section{Ethics approval and consent to participate}

The study was approved by the Ethics Committee of Second People's Hospital of Qinzhou (Qinzhou, China). Written informed consent was obtained from all patients in the study.

\section{Patient consent for publication}

Not applicable.

\section{Competing interests}

The authors declare that they have no competing interests.

\section{References}

1. Molina JR, Yang P, Cassivi SD, Schild SE and Adjei AA Non-small cell lung cancer: Epidemiology, risk factors, treatment, and survivorship. Mayo Clin Proc 83: 584-594, 2008.

2. Carney DN and Hansen HH: Non-small-cell lung cancer-stalemate or progress? N Engl J Med 343: 1261-1262, 2000.

3. Sánchez de Cos J, Sojo González MA, Montero MV, Pérez Calvo MC, Vicente MJ and Valle MH: Non-small cell lung cancer and silent brain metastasis. Survival and prognostic factors. Lung Cancer 63: 140-145, 2009.

4. Suresh R, Ali S, Ahmad A, Philip PA and Sarkar FH: The role of cancer stem cells in recurrent and drug-resistant lung cancer. Adv Exp Med Biol 890: 57-74, 2016.

5. Hwang HW and Mendell JT: MicroRNAs in cell proliferation, cell death, and tumorigenesis. Br J Cancer 96 (Suppl): R40-R44, 2007.

6. Bartel DP: MicroRNAs: Genomics, biogenesis, mechanism, and function. Cell 116: 281-297, 2004.
7. $\mathrm{Xu} \mathrm{X}$, Zhu S, Tao Z and Ye S: High circulating miR-18a, miR-20a, and miR-92a expression correlates with poor prognosis in patients with non-small cell lung cancer. Cancer Med 7: 21-31, 2018.

8. Liang Z, Kong R, He Z, Lin LY, Qin SS, Chen CY, Xie ZQ, Yu F, Sun GQ, Li CG, et al: High expression of miR-493-5p positively correlates with clinical prognosis of non small cell lung cancer by targeting oncogene ITGB1. Oncotarget 8: 47389-47399, 2017.

9. Zhang X, Ke X, Pu Q, Yuan Y, Yang W, Luo X, Jiang Q, Hu X, Gong Y, Tang K, et al: MicroRNA-410 acts as oncogene in NSCLC through downregulating SLC34A2 via activating Wnt//-catenin pathway. Oncotarget 7: 14569-14585, 2016.

10. Okuyemi OT, Piccirillo JF and Spitznagel E: TNM staging compared with a new clinicopathological model in predicting oral tongue squamous cell carcinoma survival. Head Neck 36: 1481-1489, 2014.

11. Livak KJ and Schmittgen TD: Analysis of relative gene expression data using real-time quantitative PCR and the 2(-Delta Delta C(T)) method. Methods 25: 402-408, 2001.

12. Zhang B, Pan X, Cobb GP and Anderson TA: microRNAs as oncogenes and tumor suppressors. Dev Biol 302: 1-12, 2007.

13. Skrzypski M, Dziadziuszko R and Jassem J: MicroRNA in lung cancer diagnostics and treatment. Mutat Res 717: 25-31, 2011

14. Gu Y, Cheng Y, Song Y, Zhang Z, Deng M, Wang C, Zheng G and He Z: MicroRNA-493 suppresses tumor growth, invasion and metastasis of lung cancer by regulating E2F1. PLoS One 9: e102602, 2014

15. Min L, Wang F, Hu S, Chen Y, Yang J, Liang S and Xu X: Aberrant microRNA-137 promoter methylation is associated with lymph node metastasis and poor clinical outcomes in non-small cell lung cancer. Oncol Lett 15: 7744-7750, 2018.

16. Kanaoka R, Iinuma H, Dejima H, Sakai T, Uehara H, Matsutani $\mathrm{N}$ and Kawamura M: Usefulness of plasma exosomal MicroRNA-451a as a noninvasive biomarker for early prediction of recurrence and prognosis of non-small cell lung cancer. Oncology 94: 311-323, 2018.

17. Zhang J, Wang T, Zhang Y, Wang H, Wu Y, Liu K and Pei C: Upregulation of serum miR-494 predicts poor prognosis in non-small cell lung cancer patients. Cancer Biomark 21: 763-768, 2018.

18. Shan X, Wen W, Zhu D, Yan T, Cheng W, Huang Z, Zhang L, Zhang $\mathrm{H}$, Wang $\mathrm{T}$, Zhu W, et al: $\mathrm{miR} 1296-5 \mathrm{p}$ inhibits the migration and invasion of gastric cancer cells by repressing ERBB2 expression. PLoS One 12: e0170298, 2017.

19. Chen G, He M, Yin Y, Yan T, Cheng W, Huang Z, Zhang L, Zhang H,Liu P,Zhu W and Zhu Y: miR-1296-5p decreases ERBB2 expression to inhibit the cell proliferation in ERBB2-positive breast cancer. Cancer Cell Int 17: 95, 2017.

20. Xu Q, Liu X, Liu Z, Zhou Z, Wang Y, Tu J, Li L, Bao H, Yang L and Tu K: MicroRNA-1296 inhibits metastasis and epithelial-mesenchymal transition of hepatocellular carcinoma by targeting SRPK1-mediated PI3K/AKT pathway. Mol Cancer 16: 103, 2017.

21. Stewart DJ: Wnt signaling pathway in non-small cell lung cancer. J Natl Cancer Inst 106: djt356, 2014.

This work is licensed under a Creative Commons Attribution-NonCommercial-NoDerivatives 4.0 International (CC BY-NC-ND 4.0) License. 